\title{
Pharmacological characterization of novel synthetic opioids (NSO) found in the recreational drug marketplace
}

\author{
Michael H. Baumann ${ }^{\mathrm{a},}{ }^{*}$, Susruta Majumdar ${ }^{\mathrm{b}}$, Valerie Le Rouzic ${ }^{\mathrm{b}}$, Amanda Hunkele ${ }^{\mathrm{b}}$, \\ Rajendra Uprety ${ }^{\mathrm{b}}$, Xi Ping Huang ${ }^{\mathrm{c}}$, Jin Xu ${ }^{\mathrm{b}}$, Bryan L. Roth ${ }^{\mathrm{c}}$, Ying-Xian Pan ${ }^{\mathrm{b}}$, \\ Gavril W. Pasternak ${ }^{\mathrm{b}}$

\footnotetext{
a Designer Drug Research Unit, Intramural Research Program, National Institute on Drug Abuse, National Institutes of Health, Baltimore, MD 21224, USA

${ }^{b}$ Department of Neurology and Molecular Pharmacology Program, Memorial Sloan-Kettering Cancer Center, New York, NY 10021, USA

c Department of Pharmacology, University of North Carolina, Chapel Hill, NC 27599, USA
}

\section{A R T I C L E I N F O}

Article history:

Received 9 June 2017

Received in revised form

28 July 2017

Accepted 10 August 2017

Available online 12 August 2017

Keywords:

Analgesia

Butyrylfentanyl

Mu-opioid receptor

MT-45

$\mathrm{U}-47700$

\begin{abstract}
A B S T R A C T
Novel synthetic opioids (NSO) are increasingly encountered in illicit heroin and counterfeit pain pills. Many NSO are resurrected from older biomedical literature or patent applications, so limited information is available about their biological effects. Here we examined the pharmacology of three structurallydistinct NSO found in the recreational drug market: $N$-(1-(2-phenylethyl)-4-piperidinyl)- $N$-phenylbutyramide (butyrylfentanyl), 3,4-dichloro- $N$-[(1R,2R)-2-(dimethylamino)cyclohexyl]-N-methylbenzamide (U-47700) and 1-cyclohexyl-4-(1,2-diphenylethyl)piperazine (MT-45). Radioligand binding and GTP $\gamma S$ functional assays were carried out in cells transfected with murine mu- (MOR-1), delta- (DOR1) or kappa-opioid receptors (KOR-1). Antinociceptive effects were determined using the radiant heat tail flick technique in mice, and opioid specificity was assessed with the mu-opioid antagonist naloxone. Butyrylfentanyl, U-47700 and MT-45 displayed nM affinities at MOR-1, but were less potent than morphine, and had much weaker effects at DOR-1 and KOR-1. All NSO exhibited agonist actions at MOR-1 in the GTP $\gamma$ S assay. Butyrylfentanyl and U-47700 were 31- and 12-fold more potent than morphine in the tail flick assay, whereas MT-45 was equipotent with morphine. Analgesic effects were reversed by naloxone and absent in genetically-engineered mice lacking MOR-1. Our findings confirm that butyrylfentanyl, U-47700 and MT-45 are selective MOR-1 agonists with in vitro affinities less than morphine. However, analgesic potencies vary more than 30 -fold across the compounds, and in vitro binding affinity does not predict in vivo potency. Taken together, our findings highlight the risks to humans who may unknowingly be exposed to these and other NSO when taking adulterated heroin or counterfeit pain medications.
\end{abstract}

\section{Introduction}

New psychoactive substance (NPS) are synthetic alternatives to

Abbreviations: DAMGO, [D-Ala $\left.{ }^{2}, \mathrm{~N}-\mathrm{MePhe}^{4}, \mathrm{Gly}-\mathrm{ol}\right]-\mathrm{enkephalin}$; DPDPE, [D-Pen ${ }^{2}$ D-Pen ${ }^{5}$-enkephalin; DOR-1, delta-opioid receptor; GTP $\gamma \mathrm{S}$, guanosine $5^{\prime}-\mathrm{O}$ [gamma-thio]triphosphate; KOR-1, kappa-opioid receptor; MOR-1, mu-opioid receptor; MT-45, 1-cyclohexyl-4-(1,2-diphenylethyl)piperazine; NPS, new psychoactive substances; NSO, novel synthetic opioids; U-47700, 3,4-dichloro- $N$-[(1R,2R)-2(dimethylamino)cyclohexyl]- $N$-methylbenzamide; U-50,488, 2-(3,4dichlorophenyl)- $N$-methyl- $N$-[(1R,2R)-2-pyrrolidin-1-ylcyclohexyl]acetamide.

* Corresponding author. Designer Drug Research Unit IRP, NIDA, NIH, 333 Cassell Drive, Suite 4400, Baltimore, MD 21224, USA.

E-mail address: mbaumann@mail.nih.gov (M.H. Baumann). more traditional drugs of abuse, specifically engineered to circumvent existing drug control laws (Madras, 2017). The emergence of NPS is a global phenomenon fueled by the growth of internet commerce and manufacturing capacity of Asian countries (Brandt et al., 2014). More than 600 different NPS have been identified worldwide by the United Nations Office of Drugs and Crime since 2008 (United Nations Office of Drugs and Crime, 2016). While synthetic stimulants and cannabinoids are the most common types of NPS, an increasing number of synthetic opioids are being encountered in the recreational (i.e., non-medical) drug market in the United States (US) and elsewhere (Prekupec et al., 2017). Novel synthetic opioids (NSO) include various fentanyl analogs and non-fentanyl compounds which exhibit agonist actions at 
mu-opioid receptors (MOR-1)(see Fig. 1 for chemical structures). Fentanyl is a prescribed medication that is 50- to 100-times more potent than morphine (Suzuki and El-Haddad, 2017; Vucković et al., 2009), but most fentanyl in the recreational drug market is manufactured by Chinese laboratories and trafficked via the internet, much like other NPS (US-China Economic and Security Review Commission, 2017). At present, the US is experiencing an epidemic of opioid-related overdose deaths, and this crisis is being exacerbated by the prevalence of fentanyl and NSO in products sold as heroin or pain medications (Gladden et al., 2016; Green and Gilbert, 2016; Rudd et al., 2016).

Recent data from law enforcement agencies in the US show that illicitly manufactured fentanyl is the predominant synthetic opioid confiscated (e.g., Drug Enforcement Administration, 2016a). However, many fentanyl analogs and structurally-distinct non-fentanyl opioid receptor agonist are being encountered, and this trend is expected to continue (Prekupec et al., 2017). Butyrylfentanyl is an example of a fentanyl analog that has appeared in the recreational drug marketplace as a heroin adulterant (Drug Enforcement Administration, 2016b). Butyrylfentanyl was first mentioned in the scientific literature during the 1980s and is reportedly 7-fold more potent than morphine in the mouse acetic acid writhing assay (Higashikawa and Suzuki, 2008; Woods et al., 1988). A number of opioid-related overdose deaths have been attributed to butyrylfentanyl and are documented in the forensic literature (McIntyre et al., 2016; Poklis et al., 2016). U-47700 is an example of a non-fentanyl benzamide compound that has emerged as a heroin adulterant and constituent of counterfeit pain pills (Armenian et al., 2017; Drug Enforcement Administration, 2016c). U-47700 was originally investigated as an analgesic agent by the Upjohn Company in the late 1970s and is 8-fold more potent than morphine in mouse antinociception assays (Cheney et al., 1985; Szmuszkowicz and inventor, 1978). U-47700 served as an important lead compound in the development of selective kappa-opioid agonists like 2-(3,4-dichlorophenyl)- $N$-methyl- $N$-[(1R,2R)-2-pyrrolidin-1ylcyclohexyl]acetamide (U50,488). U-47700 has been implicated in a number of recent overdose deaths (Elliott et al., 2016; Mohr et al.,
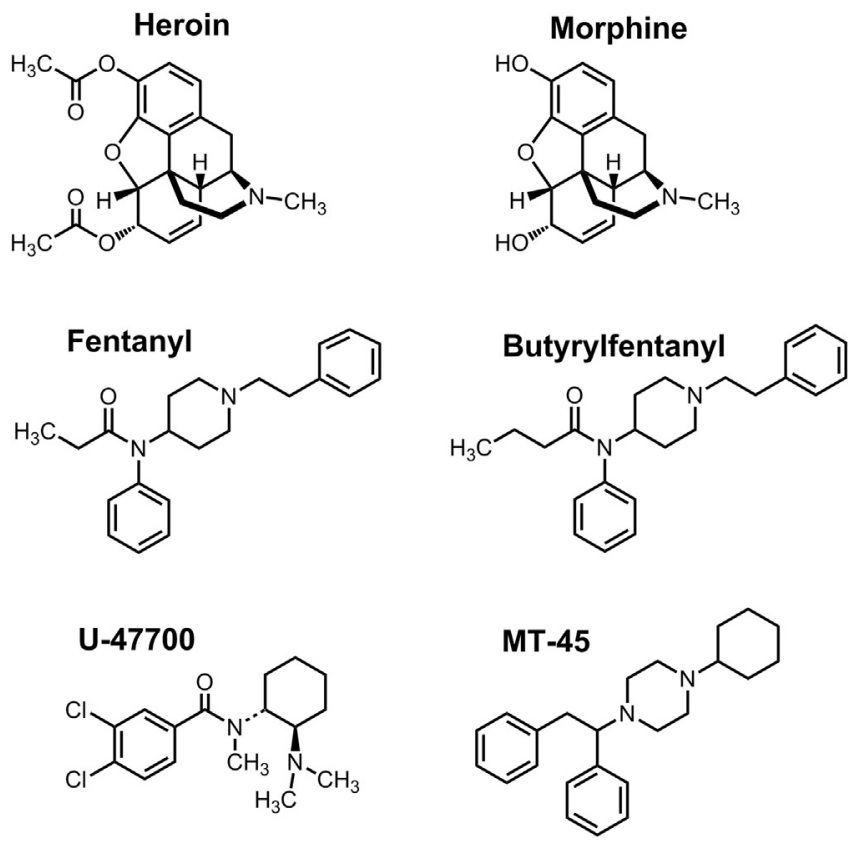

Fig. 1. Chemical structures of novel synthetic opioids (NSO) as compared to heroin and morphine. U-47700 is 3,4-dichloro- $N$-[(1R,2R)-2-(dimethylamino)cyclohexyl]-Nmethylbenzamide whereas MT-45 is 1-cyclohexyl-4-(1,2-diphenylethyl)piperazine.
2016). MT-45 is a non-fentanyl compound first developed by the Dainippon Pharmaceutical Company in the 1970s as an analgesic agent (Nishimura et al., 1976). While MT-45 is rarely encountered in the US, the compound has been associated with multiple deaths in European countries (EMCDDA, 2014; Siddiqi et al., 2015).

The widespread availability of compounds like butyrylfentanyl, U-47700 and MT-45 represents a serious public health concern, because humans are often unknowingly exposed to these agents (Amlani et al., 2015; Drug Enforcement Administration, 2016d). Additionally, there is little up-to-date information about the biological effects of these drugs, most of which were studied decades ago using diverse in vitro and in vivo research approaches that are now replaced by newer methods (Suzuki and El-Haddad, 2017; Prekupec et al., 2017). In particular, the cloning of opioid receptor genes has enabled the generation of cell lines expressing pure populations of opioid receptor subtypes, and the generation of genetically-engineered mice lacking these same receptors. Therefore, the purpose of the present study was to carry out a side-byside comparison of the pharmacology of NSO and the prototypical mu agonist morphine, using standard opioid-related assay methods. We examined the effects of butyrylfentanyl, U-47700 and MT-45 in radioligand binding and GTP $\gamma \mathrm{S}$ functional assays in cells transfected with mouse MOR-1, delta-opioid receptors (DOR-1) or kappa-opioid receptors (KOR-1) (Bolan et al., 2004). Broad receptorome screening was carried out to identify potential non-opioid sites of action (Kroeze et al., 2015). Antinociceptive effects of the drugs were determined using the radiant heat tail flick assay in mice, and opioid specificity was evaluated using naloxone pretreatment (Majumdar et al., 2011b). Tail flick assays were also carried out in genetically-engineered knock out (KO) mice lacking specific splice variants of MOR-1 (Lu et al., 2015; Pan et al., 2009).

\section{Materials and methods}

\subsection{Drugs and chemicals}

$N$-(1-(2-Phenylethyl)-4-piperidinyl)- $N$-phenylbutyramide $\mathrm{HCl}$ (butyrylfentanyl), 3,4-dichloro- $N$-[(1R,2R)-2-(dimethylamino) cyclohexyl]- $N$-methylbenzamide (U-47700) and 1-cyclohexyl-4(1,2-diphenylethyl)piperazine $2 \mathrm{HCl}$ (MT-45) were obtained as dry powders from Cayman Chemical (Ann Arbor, MI, USA). For the in vitro assays, drug powders were diluted in DMSO to yield $10 \mathrm{mM}$ stocks that were stored frozen; on the day of an experiment, stock solutions were thawed and diluted in assay buffer. For the in vivo analgesia tests, powdered butyrylfentanyl and MT-45 were diluted in sterile water to yield the desired doses. U-47700 was diluted in sterile water with $0.25 \% \mathrm{HCl}$. 3-Iodobenzoylnaltrexamine (IBNtxA) and $\left[{ }^{125} \mathrm{I}\right] \mathrm{IBN}$ txA were synthesized in our laboratory as previously described (Majumdar et al., 2011a). Na ${ }^{125}$ I and ${ }^{35}$ S]GTP $\gamma S$ were purchased from PerkinElmer (Waltham, MA, USA). [D-Ala ${ }^{2}, \mathrm{~N}-$ MePhe ${ }^{4}$,Gly-ol]-enkephalin (DAMGO), [D-Pen ${ }^{2}$, D-Pen $\left.{ }^{5}\right]$-enkephalin (DPDPE), ( \pm )-2-(3,4-dichlorophenyl)- $N$-methyl- $N$-[(1R,2R)-2pyrrolidin-1-ylcyclohexyl]acetamide $\mathrm{HCl}(\mathrm{U}-50,488)$ and naloxone were generously provided by the National Institute on Drug Abuse (NIDA), Drug Supply Program (Rockville, MD, USA). All other chemicals and reagents were purchased from Sigma-Aldrich (St Louis, MO, USA).

\subsection{Animals}

Male CD1 mice (20-32 g) were obtained from Charles River Laboratories (Frederick, MD, USA), while male C57BL/6 J mice (20-32 g) were obtained from Jackson Laboratories (Bar Harbor, ME, USA). Exon-1/exon-11 MOR-1 knockout (E1/E11 KO) mice which lack expression of all Oprm1 splice variants were bred on a 
mixed C57BL/6 J/129Sv6 background in the animal facility at Memorial Sloan Kettering Cancer Center (MSKCC). Similarly, exon-11 $\mathrm{KO}$ (E11 KO) mice, which lack 6-transmembrane splice variants of MOR-1, were bred on a C57BL/6 J background. All mice were housed in groups of five and maintained on a $12 \mathrm{~h}$ light/dark cycle with food and water available ad libitum. Experiments were approved by the Institutional Animal Care and Use Committee of the MSKCC in accordance with the 2002 National Institutes of Health Guide for the Care and Use of Laboratory Animals. All mice used for these experiments were opioid naïve at the time of drug treatments.

\subsection{Radioligand binding assays}

$\left[{ }^{125}\right.$ I]IBNtxA (0.1 nM) competition binding assays were performed in membranes prepared from Chinese Hamster Ovary (CHO) cells stably expressing mouse MOR-1, DOR-1 or KOR-1, as previously described (Váradi et al., 2013, 2015). Binding was performed at $25^{\circ} \mathrm{C}$ for $90 \mathrm{~min}$. Binding in MOR-1/CHO cells was carried out in $50 \mathrm{mM}$ potassium phosphate buffer with $5 \mathrm{mM} \mathrm{MgSO}_{4}$ and $20 \mu \mathrm{g} / \mathrm{mL}$ protein, while binding in DOR-1/CHO and KOR-1/CHO cells was carried out in $50 \mathrm{mM}$ potassium phosphate buffer and $20 \mu \mathrm{g} / \mathrm{mL}$ protein. Eight different concentrations of butyrylfentanyl, U-47700 or MT-45 were tested to create dose-response inhibition curves. After the incubation, the reaction was rapidly filtered through glass fiber filters (Whatman Schleicher \& Schuell, Keene, $\mathrm{NH}$, USA) and washed three times with $3 \mathrm{~mL}$ of ice-cold $5 \mathrm{mM}$ Tris$\mathrm{HCl}, \mathrm{pH} 7.4$, on a semiautomatic cell harvester (Brandel, Gaithersburg, MD, USA). Nonspecific binding was defined in the presence of levallorphan $(8 \mu \mathrm{M})$ and was subtracted from total binding to yield specific binding. Ki values were calculated by nonlinear regression analysis using commercially-available software (GraphPad Prism, San Diego, CA, USA). Protein concentrations were determined using the Lowry method. The compounds were also tested by the Psychoactive Drug Screening Program (PDSP) of the National Institute of Mental Health (NIMH) to interrogate binding activity at 300 different $G$ protein-coupled receptors, as a means to identify potential non-opioid sites of action (Kroeze et al., 2015).

\section{4. ${ }^{35}$ SJGTP $\gamma$ S functional assays}

$\left.{ }^{35} \mathrm{~S}\right] \mathrm{GTP} \gamma \mathrm{S}$ binding was performed on membranes prepared from transfected cells stably expressing opioid receptors as previously described (Bolan et al., 2004; Váradi et al., 2015). Briefly, incubations were carried out for $60 \mathrm{~min}$ at $30{ }^{\circ} \mathrm{C}$ in assay buffer (50 mM Tris- $\mathrm{HCl}, \mathrm{pH} 7.4,3 \mathrm{mM} \mathrm{MgCl}, 0.2 \mathrm{mM}$ EGTA, and $100 \mathrm{mM}$ $\mathrm{NaCl}$ ), containing $\left.0.05 \mathrm{nM}{ }^{35} \mathrm{~S}\right] \mathrm{GTP} \gamma \mathrm{S} ; 20 \mu \mathrm{g} / \mathrm{mL}$ each leupeptin, pepstatin, aprotinin, and bestatin; and $30 \mu \mathrm{M}$ GDP. Eight different concentrations of butyrylfentanyl, U-47700 or MT-45 were tested to create dose-response curves. After the incubation, the reaction was rapidly filtered through glass fiber filters (Whatman Schleicher \& Schuell, Keene, NH, USA) and washed three times with $3 \mathrm{~mL}$ of ice-cold buffer ( $5 \mathrm{mM}$ Tris- $\mathrm{HCl}, \mathrm{pH} 7.4$ ) on a semiautomatic cell harvester. Filters were transferred into vials with $3 \mathrm{~mL}$ of Liquiscint (National Diagnostics, Atlanta, GA, USA), and the radioactivity in vials was determined by scintillation spectroscopy in a Tri-Carb 2900 TR counter (PerkinElmer Life Sciences, Shelton, CT, USA). Basal binding was determined in the presence of GDP and the absence of drug. $\mathrm{EC}_{50}$ and \%Emax values were calculated by nonlinear regression analysis using commercially-available software (GraphPad Prism, San Diego, CA, USA). $\mathrm{EC}_{50}$ is the drug concentration eliciting $50 \%$ of maximal response (\%Emax), which is defined by the effects of 100 nM DAMGO, DPDPE or U50-488 for the MOR-1, DOR-1 or KOR-1 assays, respectively.

\subsection{Antinociception testing}

Tail flick antinociception was determined by the radiant heat tail flick technique using an Ugo Basile model 37360 instrument, as previously described (Váradi et al., 2015). The intensity was set to achieve a baseline response between 2 and $3 \mathrm{~s}$. Baseline latencies were determined before experimental treatments for all mice, and a maximal $10 \mathrm{~s}$ latency was used to minimize damage to the tail. Raw data were transformed to percent maximal effect, \%MPE, which was calculated according to the formula: \% MPE $=[$ (observed latency - baseline latency)/(maximal latency - baseline latency) $] \times 100$. Compounds were injected subcutaneously (s.c.) and antinociception was assessed 15 min later at the peak effect. Dose-response experiments were first assessed in CD1 mice to determine $\mathrm{EC}_{50}$ values, which were calculated using commerciallyavailable software (GraphPad Prism, San Diego, CA, USA). For the antagonism studies, $1 \mathrm{mg} / \mathrm{kg}$ naloxone was administered $15 \mathrm{~min}$ before the agonist agent. Additional antinociception testing was carried out in E1/E11 KO mice, which lack all mu receptor gene expression, to confirm mu-opioid specificity of the observed effects. Finally, drugs were tested for antinociceptive actions in E11 $\mathrm{KO}$ mice to identify potential contributions of different sets of splice variants (Majumdar et al., 2011b; Pan et al., 2009).

\section{Results}

\subsection{Results from in vitro binding methods}

Table 1 summarizes the results for displacement of [ ${ }^{125}$ I]IBNtxA binding in CHO cells expressing mouse MOR-1, DOR-1 and KOR-1. Butyrylfentanyl, U-47700 and MT-45 displayed similar muselective effects on binding, with Ki values ranging from 18 to $57 \mathrm{nM}$ at MOR-1. Butyrylfentanyl and U-47700 had at least 10 -fold greater affinity for MOR-1 when compared to their effects at DOR-1 and KOR-1. MT-45 was somewhat less mu-selective, with 13- and 4fold greater affinity at MOR-1 versus DOR-1 and KOR-1, respectively. Interestingly, all of the NSO tested were less potent than morphine at inhibiting [ ${ }^{125}$ I]IBNtxA binding to MOR-1. Findings from the PDSP receptorome screening corroborated our findings in CHO cells, and demonstrated that butyrylfentanyl, U-47700 and MT-45 inhibited [ ${ }^{3} \mathrm{H}$ ]DAMGO binding to MOR-1, but the drugs had much weaker effects at DOR- 1 and KOR-1. No other non-opioid sites of action were identified for the compounds when tested (10 $\mu \mathrm{M})$ across an array of $G$ protein-coupled receptors (data not shown).

Table 2 summarizes the effects of NSO in the $\left[{ }^{35} \mathrm{~S}\right] \mathrm{GTP} \gamma \mathrm{S}$ functional assay in cells expressing MOR-1, DOR-1 or KOR-1. Consistent with the radioligand binding results, butyrylfentanyl, U-47700 and MT-45 acted as selective and efficacious mu-opioid agonists, with potencies ranging from 43 to $214 \mathrm{nM}$ at MOR-1. U-47700 displayed

Table 1

Binding affinities for NSO at opioid receptor subtypes as compared to morphine.

\begin{tabular}{lllll}
\hline Ligand & MOR-1 & DOR-1 & KOR-1 & *MOR-1 \\
& Binding & Binding & Binding & Binding \\
& Ki $(n M)$ & Ki $(n M)$ & Ki (nM) & Ki (nM) \\
\hline Morphine & $5.0 \pm 0.6$ & N.D. & N.D. & $3.5 \pm 0.8$ \\
Butyrylfentanyl & $18 \pm 5$ & $286 \pm 56$ & $3174 \pm 410$ & $18 \pm 2$ \\
U-47700 & $57 \pm 21$ & $1105 \pm 223$ & $653 \pm 163$ & $39 \pm 4$ \\
MT-45 & $44 \pm 17$ & $606 \pm 19$ & $204 \pm 15$ & $44 \pm 6$ \\
\hline
\end{tabular}

$\left[{ }^{125}\right.$ I]IBNtxA binding was carried out in cells expressing MOR-1, DOR- 1 or KOR-1 as described in Materials and Methods. Data are mean \pm SEM for $\mathrm{N}=3$ experiments performed in triplicate. N.D. indicates not determined. * Comparator MOR-1 data obtained from NIMH Psychoactive Drug Screening Program (PDSP) using [ $\left.{ }^{3} \mathrm{H}\right]$ DAMGO as the tritiated ligand. Information about assay methods can be found at http://pdsp.med.unc.edu/pdsp/binding.php. 
Table 2

Functional activities for NSO at opioid receptor subtypes in the GTP $\gamma \mathrm{S}$ assay.

\begin{tabular}{|c|c|c|c|c|c|c|}
\hline \multirow[t]{2}{*}{ Ligand } & \multicolumn{2}{|l|}{ MOR-1 } & \multicolumn{2}{|l|}{ DOR-1 } & \multicolumn{2}{|l|}{ KOR-1 } \\
\hline & $\mathrm{EC}_{50}(\mathrm{nM})$ & \%Emax & $\mathrm{EC}_{50}(\mathrm{nM})$ & \%Emax & $\mathrm{EC}_{50}(\mathrm{nM})$ & \%Emax \\
\hline Butyrylfentanyl & $43 \pm 5$ & $76 \pm 1$ & $910 \pm 628$ & $43 \pm 5$ & $1236 \pm 625$ & $39 \pm 1$ \\
\hline U-47700 & $214 \pm 23$ & $97 \pm 2$ & $5161 \pm 1357$ & $62 \pm 1$ & $2699 \pm 769$ & $53 \pm 1$ \\
\hline MT-45 & $124 \pm 12$ & $71 \pm 7$ & $3250 \pm 1074$ & $49 \pm 1$ & inactive & inactive \\
\hline
\end{tabular}

$\left[{ }^{35} \mathrm{~S}\right] \mathrm{GTP} \gamma \mathrm{S}$ binding was performed in cells expressing MOR-1, DOR-1 or KOR-1 as described in Materials and Methods. Data are mean \pm SEM for $\mathrm{N}=3$ experiments performed in triplicate. Potency is measured as $\mathrm{EC}_{50}$ while efficacy is \% of maximal effect (\% Emax).

full efficacy at MOR-1, while butyrylfentanyl and MT-45 were somewhat less efficacious as compared to the prototypic MOR-1 agonist DAMGO. All NSO displayed at least 10 -fold greater potency at MOR-1 when compared to effects at DOR-1 and KOR-1. Butyrylfentanyl and U-47700 were weak partial agonists at DOR1 and KOR-1, whereas MT-45 was a partial agonist at DOR-1 and inactive at KOR-1 when compared to the prototypic DOR-1 agonist DPDPE or KOR-1 agonist U50,488.

\subsection{Results from in vivo antinociception assays}

Fig. 2 depicts the dose-response effects of NSO and morphine in the radiant heat tail flick assay in male CD1 mice. All compounds evoked dose-dependent and efficacious antinociceptive actions with the rank order of potency: butyrylfentanyl $>U-47700>$ MT$45=$ morphine. Table 3 shows potency estimates for the compounds, expressed as $\mathrm{EC}_{50}$ values, and demonstrates that butyrylfentanyl $\left(\mathrm{EC}_{50}=0.08 \mathrm{mg} / \mathrm{kg}\right.$, s.c.) was 31 -fold more potent than morphine $\left(\mathrm{EC}_{50}=2.5 \mathrm{mg} / \mathrm{kg}\right.$, s.c. $)$ while $\mathrm{U}-47700\left(\mathrm{EC}_{50}=0.21 \mathrm{mg} /\right.$ $\mathrm{kg}$, s.c.) was 12 -fold more potent than morphine in vivo.

Fig. 3 shows the time-course of antinociceptive effects for NSO as compared to morphine in CD1 mice. The time of peak antinociception activity was similar across the compounds after s.c. administration, but butyrylfentanyl $(0.2 \mathrm{mg} / \mathrm{kg})$ and $\mathrm{U}-47700$ $(0.75 \mathrm{mg} / \mathrm{kg})$ had more transient effects than MT-45 $(5 \mathrm{mg} / \mathrm{kg})$ and morphine $(4.5 \mathrm{mg} / \mathrm{kg})$. Fig. 4 depicts the effects of naloxone pretreatment on antinociceptive effects of NSO and morphine. Administration of $1 \mathrm{mg} / \mathrm{kg}$ s.c. naloxone completely blocked the antinociceptive effects of s.c. butyrylfentanyl $(0.2 \mathrm{mg} / \mathrm{kg}), \mathrm{U}-47700$ (0.75 mg/kg), MT-45 (5 mg/kg) and morphine (4.5 mg/kg), confirming the opioid specificity of the observed actions.

Fig. 5 depicts analgesic actions of NSO in mice lacking exon-1 and exon-11 variants of MOR-1 (E1/E11 KO) and their wildtype counterparts (mixed C57/BJ6/129Sv6). Table 3 summarizes $\mathrm{EC}_{50}$ values. All three NSO showed loss of analgesic actions in E1/E11 KO

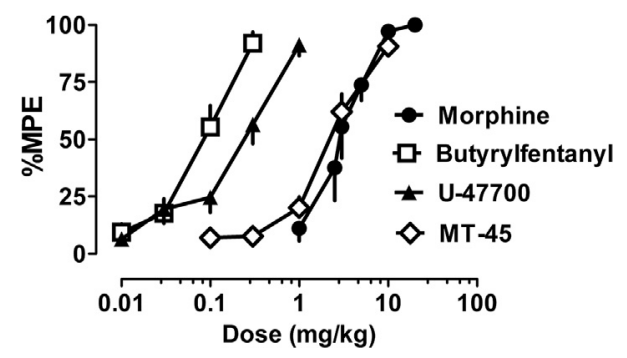

Fig. 2. Cumulative dose-response effects for morphine and NSO in the radiant heat tail flick assay carried out in CD1 mice. Morphine, butyrylfentanyl, U-47700 or MT-45 were administered s.c. and tail flick assays were carried out as described in Materials and Methods. Data are mean \pm SEM for $\mathrm{N}=6$ mice per group, expressed as percentage of maximal possible effect (\%MPE). Experiments were replicated twice with similar results. mice, confirming MOR-1 as the primary target of action for these drugs. We also investigated the effects of NSO in mice lacking the exon-11 MOR-1 splice variants (E11 KO), since we have previously shown this receptor variant is involved in analgesic actions of certain compounds (Majumdar et al., 2011b; Pan et al., 2009; Grinnell et al., 2016). As shown in Fig. 6 and summarized in Table 3, the effects of NSO were less potent in C57BL/6 J WT mice when compared to their effects in CD1 mice, but there were no significant differences in antinociceptive potencies between E11 KO mice and their C57/B6J WT counterparts. The data with E11 KO mice confirm that NSO display antinociceptive actions via a mechanism analogous to morphine, which retains full analgesic activity in the E11 KO mice (Pan et al., 2009; Marrone et al., 2017).

\section{Discussion}

The US is currently experiencing an epidemic of opioid-related overdose deaths, and this phenomenon is exacerbated by the increasing availability of illicitly manufactured fentanyl in the recreational drug marketplace (Frank and Pollack, 2017; Gladden et al., 2016; Rudd et al., 2016). A disturbing new trend in this regard is the emergence of structurally-diverse NSO as standalone products, adulterants in illicit heroin or constituents of counterfeit pain medications (Drug Enforcement Administration, 2016a; Prekupec et al., 2017). Most NSO are resurrected from older biomedical literature or patent applications, so there is scant information about their biological effects (Suzuki and El-Haddad, 2017). Thus, the purpose of the present investigation was to examine the pharmacological effects of three commonly encountered NSO as compared to the prototypical mu-opioid agonist morphine. We found that butyrylfentanyl, U-47700 and MT-45 act as selective MOR-1 agonists in vitro, but binding affinities for the compounds do not predict their analgesic potencies in vivo. Importantly, butyrylfentanyl and U-47700 are 31- and 12-fold more potent than morphine as analgesic agents in vivo, suggesting these compounds and their structural analogs could pose significant public health risks, including the possibility of fatal overdose (see Elliott et al., 2016; McIntyre et al., 2016; Mohr et al., 2016; Poklis et al., 2016).

Our radioligand binding results with butyrylfentanyl, U-47700 and MT-45 represent the first investigation of the compounds in cells transfected with MOR-1, DOR-1 and KOR-1. Prior literature has reported effects of the drugs in receptor binding assays using brain tissue from rats or guinea pigs, and a variety of tritiated ligands (Alburges et al., 1992; Cheney et al., 1985; Fujimura et al., 1978; Loew et al., 1988). We found that butyrylfentanyl, U-47700 and MT-45 display Ki values at MOR-1 ranging from 18 to $57 \mathrm{nM}$ (see Table 1), whereas the drugs have much weaker effects on binding at DOR-1 and KOR-1. Our results with butyrylfentanyl agree with those of Alburges et al. (1992) who showed the compound inhibits binding of $\left[{ }^{3} \mathrm{H}\right]$ fentanyl in rat brain tissue with an $\mathrm{IC}_{50}$ of $32 \mathrm{nM}$. We observed that U-47700 displays a $\mathrm{Ki}$ of $57 \mathrm{nM}$ at mu-opioid receptors, but prior studies report a broad range of affinity values. For example, Cheney et al. (1985) found that U-47700 exhibits a Ki of $110 \mathrm{nM}$ for inhibiting $\left[{ }^{3} \mathrm{H}\right]$ naloxone binding in rat brain, whereas Loew et al. (1988) found a Ki of $5 \mathrm{nM}$ for inhibiting [ ${ }^{3} \mathrm{H}$ ]DAMGO in guinea pig brain. The Ki of MT- 45 that we observed for inhibition of opioid agonist binding is indicative of greater potency than reported previously for inhibition of opioid antagonist binding. Fujimura et al. (1978) and Nozaki et al. (1983) both demonstrated that MT-45 inhibits $\left[{ }^{3} \mathrm{H}\right]$ naloxone binding to mu receptors in rat brain tissue with an $\mathrm{IC}_{50}$ of about $700 \mathrm{nM}$. It seems probable that discrepancies in mu receptor binding affinities across studies are related to different assay methods and radioligands employed, though the present data show that structurally-distinct NSO exhibit similar binding affinities at MOR-1 when labeled with either $\left[{ }^{125} \mathrm{I}\right]$ 
Table 3

Antinociceptive potency of NSO in the mouse tail flick assay.

\begin{tabular}{|c|c|c|c|c|c|}
\hline Ligand & $\begin{array}{l}\mathrm{ED}_{50} \\
\text { (mg/kg, s.c.) } \\
\text { CD1 }\end{array}$ & $\begin{array}{l}\mathrm{ED}_{50} \\
\text { (mg/kg, s.c.) } \\
\text { C57/129 WT }\end{array}$ & $\begin{array}{l}\mathrm{ED}_{50} \\
\text { (mg/kg, s.c.) } \\
\text { E1/E11 KO }\end{array}$ & $\begin{array}{l}\mathrm{ED}_{50} \\
\text { (mg/kg, s.c.) } \\
\text { C57BL/6 J WT }\end{array}$ & $\begin{array}{l}\mathrm{ED}_{50} \\
\text { (mg/kg, s.c.) } \\
\text { Exon-11 KO }\end{array}$ \\
\hline Morphine & $\begin{array}{l}2.5 \\
(1.8-3.5)\end{array}$ & N.D. & N.D. & N.D. & N.D. \\
\hline Butyrylfentanyl & $\begin{array}{l}0.08 \\
(0.06-0.11)\end{array}$ & $\begin{array}{l}0.21 \\
(0.01-0.45)\end{array}$ & Inactive & $\begin{array}{l}0.16 \\
(0.09-0.31)\end{array}$ & $\begin{array}{l}0.12 \\
(0.04-0.33)\end{array}$ \\
\hline U-47700 & $\begin{array}{l}0.21 \\
(0.16-0.29)\end{array}$ & $\begin{array}{l}0.49 \\
(0.28-0.89)\end{array}$ & Inactive & $\begin{array}{l}0.55 \\
(0.29-1.06)\end{array}$ & $\begin{array}{l}0.49 \\
(0.29-0.86)\end{array}$ \\
\hline MT-45 & $\begin{array}{l}2.3 \\
(1.7-3.0)\end{array}$ & $\begin{array}{l}5.17 \\
(2.78-9.62)\end{array}$ & Inactive & $\begin{array}{l}6.3 \\
(2.9-13.5)\end{array}$ & $\begin{array}{l}5.8 \\
(2.5-13.2)\end{array}$ \\
\hline
\end{tabular}

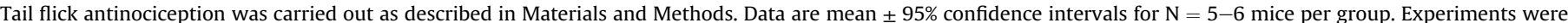
replicated twice with similar results. Potency is measured as $\mathrm{EC}_{50}$. N.D. is not determined, while 'inactive' indicates no antinociceptive activity.

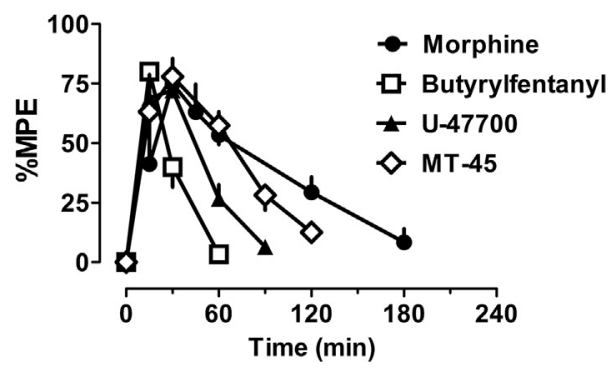

Fig. 3. Time-course effects for morphine and NSO in the radiant heat tail flick assay carried out in CD1 mice. Mice received s.c. morphine $(4.5 \mathrm{mg} / \mathrm{kg})$, butyrylfentanyl $(0.2 \mathrm{mg} / \mathrm{kg}), \mathrm{U}-47700(0.75 \mathrm{mg} / \mathrm{kg})$ or MT-45 (5 mg/kg). Tail flick responses were monitored up to 180 min post-injection. Data are mean \pm SEM for $\mathrm{N}=6$ mice per group, expressed as percent of maximal possible effect (\%MPE). Experiments were replicated twice with similar results.

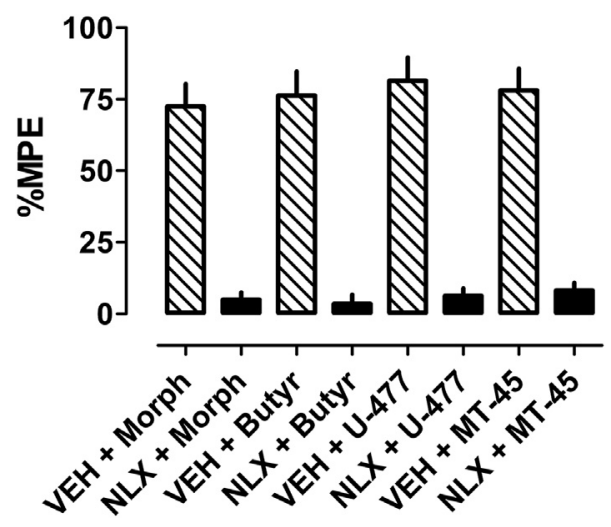

Fig. 4. Effects of naloxone on antinociception produced by morphine and NSO in CD1 mice. Mice received s.c. naloxone (NLX, $1 \mathrm{mg} / \mathrm{kg}$ ) or saline vehicle (VEH) $15 \mathrm{~min}$ prior to injection of morphine (Morph, $4.5 \mathrm{mg} / \mathrm{kg}$ ), butyrylfentanyl (Butyr, $0.2 \mathrm{mg} / \mathrm{kg}$ ), U-47700 $(\mathrm{U}-477,0.75 \mathrm{mg} / \mathrm{kg}$ ) or MT-45 $(5 \mathrm{mg} / \mathrm{kg})$. Data are mean $\pm \mathrm{SEM}$, expressed as percent maximal possible effect (\%MPE) at the time of peak analgesic effect.

BNtxA or $\left[{ }^{3} \mathrm{H}\right]$ DAMGO. Overall, our binding results from $\mathrm{CHO}$ cells and receptorome screening methods show that all NSO tested display less affinity for MOR- 1 when compared to the prototypical mu-opioid agonist morphine.

The $\left.{ }^{35} \mathrm{~S}\right] \mathrm{GTP} \gamma \mathrm{S}$ binding assay is used to assess functional coupling between opioid receptor binding events and intracellular transduction pathways, thereby providing an index of drug efficacy (Selley et al., 1997). To the best of our knowledge, the present findings are the only data available for effects of butyrylfentanyl, U47700 and MT-45 in the GTP $\gamma \mathrm{S}$ assay. We show that all three NSO are efficacious agonists at MOR- 1 with potencies ranging from 43 to $214 \mathrm{nM}$ (see Table 2), while the drugs have much weaker effects at DOR-1 and KOR-1. Our data agree with older literature demonstrating opioid agonist activity for butyrylfentanyl and MT-45 using in vitro preparations such as guinea pig ileum or mouse vas deferens (Fujimura et al., 1978; Woods et al., 1988), where opioid agonists induce inhibition of electrically-evoked smooth muscle contractions (Hayes et al., 1985). Woods et al. (1988) showed that butyrylfentanyl displays an $\mathrm{IC}_{50}$ of $442 \mathrm{nM}$ for inhibiting muscle contractions in the mouse vas deferens, whereas Fujimura et al. (1978) showed MT-45 has an $\mathrm{IC}_{50}$ of $15 \mathrm{nM}$ in the guinea pig ileum assay. We found that MT-45 exhibits an unusual profile of functional activity at opioid receptor subtypes, acting as an efficacious agonist at MOR-1, a weak partial agonist at DOR-1, while being inactive at KOR-1 (see Table 2). It is tempting to speculate that the unique in vitro pharmacology of MT-45 might underlie its unusual clinical side-effects which include a deep level of unconsciousness, ototoxicity, hair loss and dermatitis (Helander et al., 2014, 2017).

The ability of MOR-1 agonists to induce antinociception in rodent models is a valid predictor of pain relief, and other opioidmediated effects, in clinical settings (Pasternak, 2014). Here we demonstrate that butyrylfentanyl, U-47700 and MT-45 act as MOR-1 agonists in vivo and induce efficacious analgesic actions similar to the effects of morphine. Importantly, butyrylfentanyl and U-47700 are 31- and 12-fold more potent than morphine in the mouse radiant heat tail flick test (see Fig. 2 and Table 3). The present in vivo results agree qualitatively with previous findings examining the analgesic effects of NSO studied here, but there are noteworthy differences in drug potency versus effects of morphine. Higashikawa and Suzuki (2008) reported that orally administered butyrylfentanyl and morphine display $\mathrm{EC}_{50}$ values of 0.05 and $0.33 \mathrm{mg} / \mathrm{kg}$ for analgesic activity in the mouse acetic acid writhing assay, indicating butyrylfentanyl is 7-fold more potent than morphine. By contrast, we found that s.c. administered butyrylfentanyl is 31-fold more potent than morphine in the tail flick assay. Cheney et al. (1985) showed that s.c. administered U47700 and morphine have $\mathrm{EC}_{50}$ values of 0.2 and $1.5 \mathrm{mg} / \mathrm{kg}$ for analgesic activity in the mouse tail flick assay, indicating U-47700 is 7.5 -fold more potent than morphine. We found that U-47700 is 12 -fold more potent than morphine in an assay system similar to the one employed by Cheney and coworkers. Our in vivo data show that MT-45 and morphine have nearly identical analgesic potency, and this observation agrees with the work of Natsuka et al. (1975) who found that MT-45 exhibits similar potency to morphine in the mouse phenylquinone writhing assay and tail flick test in mice. Finally, we demonstrate that pretreatment with 

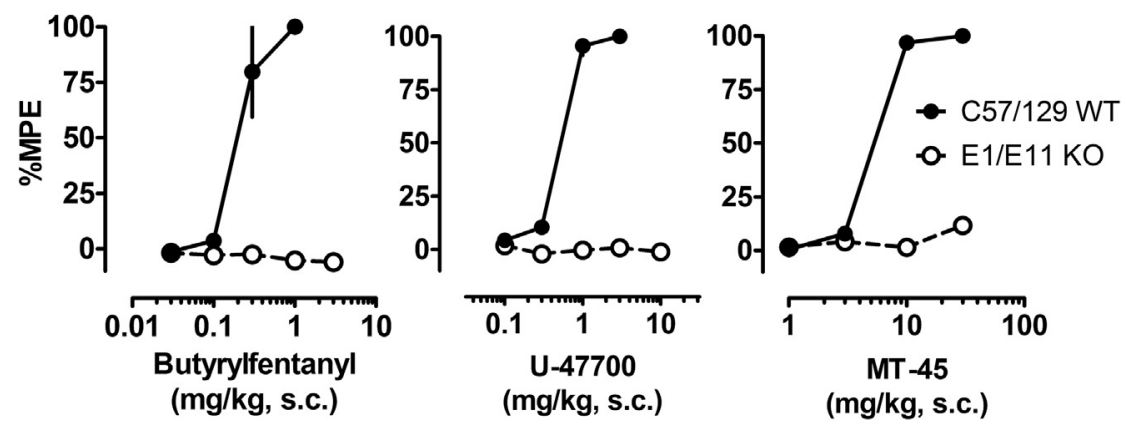

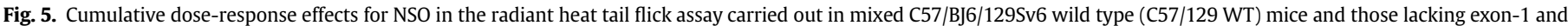

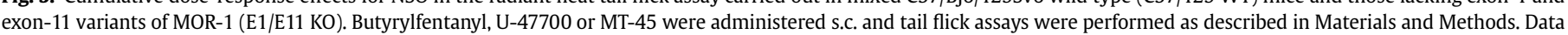
are mean \pm SEM for $\mathrm{N}=5$ mice per group, expressed as percentage of maximal possible effect (\%MPE).
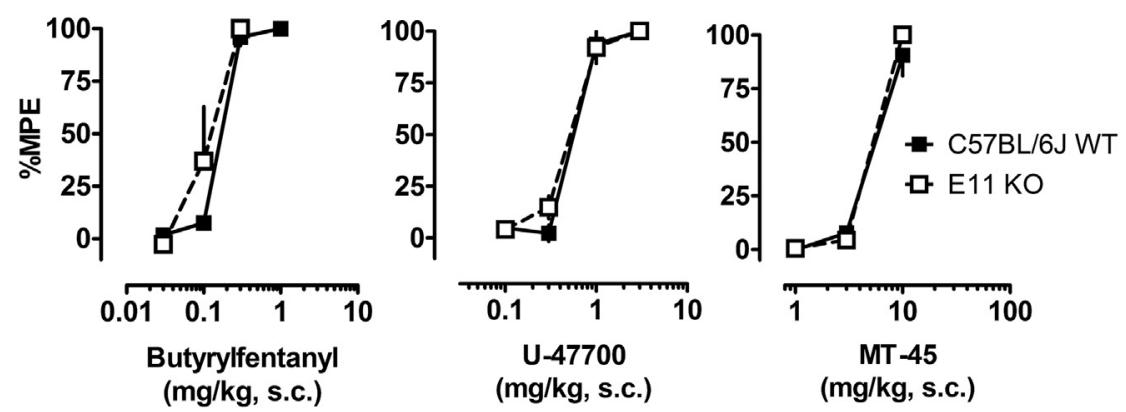

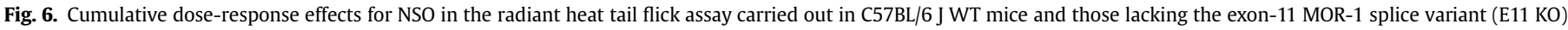

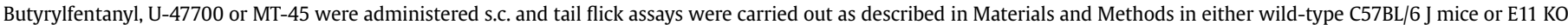
mice. Data are mean \pm SEM for $\mathrm{N}=5$ mice per group, expressed as percentage of maximal possible effect (\%MPE).

the mu-opioid antagonist naloxone is capable of completely reversing the antinociceptive effects of butyrylfentanyl, U-47700 and MT-45.

To further explore the role of MOR-1 in mediating the in vivo effects of NSO, we examined the antinociceptive effects of the drugs in genetically-engineered mice lacking specific splice variants of MOR-1. In E1/E11 KO mice lacking all mu-opioid receptor gene expression, butyrylfentanyl, U-47700 and MT-45 failed to elicit antinociceptive effects when compared to their WT counterparts. We also tested effects of the drugs in E11 KO mice, which lack 6transmembrane MOR-1 splice variants, since prior evidence shows that effects of certain opioid agonists (e.g., buprenorphine) are greatly reduced in this genotype, while morphine retains full activity. In E11 KO mice, all of the drugs displayed analgesic potencies that were nearly identical to their WT counterparts, suggesting no role for the E11 splice variant in the effects observed. Collectively, the total loss of analgesia in E1/E11 KO mice, coupled with the normal analgesic effects in E11 KO mice, confirm that the three NSO tested act through traditional, full length mu receptors, in a manner analogous to morphine.

To summarize, we demonstrate that three commonly encountered NSO are efficacious MOR-1 agonists as determined in vitro and in vivo. In general, the present findings support older preclinical literature describing the pharmacology of butyrylfentanyl, U-47700 and MT-45 in rodent models. However, we show that in vitro binding affinities and functional activities for the drugs do not predict in vivo analgesic potencies. Stated more simply, butyrylfentanyl and U-47700 exhibit lower affinity than morphine at MOR-1 yet are much more potent than morphine in the mouse tail flick test. One plausible reason for the greater-than-predicted analgesic potencies for butyrylfentanyl and U-47700 could be their enhanced brain penetration owing to higher lipophilicity.
Morphine is a moderately polar molecule ( $\log \mathrm{P}=0.57)$, but butyrylfentanyl (clogP 4.15) and U-47700 (clogP 4.09) are significantly more hydrophobic based on physiochemical predictions. Other possibilities for the disconnect between in vitro and in vivo potencies might be related to differences in intrinsic efficacy or cell-signal amplification across the various drugs tested. Whether our findings in mice can be extrapolated to the effects of the drugs in humans is uncertain, but the data illustrate the potential risks to humans who are unknowingly exposed to NSO as adulterants in illicit heroin or constituents of counterfeit pain pills (Armenian et al., 2017; Gladden et al., 2016; Mohr et al., 2016; Rudd et al., 2016). Another critical question is whether antinociceptive potency estimates can be related to dangerous side-effects such as respiratory depression and lethality. With respect to fentanyl and its analogs, it appears that potency from antinociceptive assays in mice can be used to predict potency of drugs to induce adverse effects in this species (Suzuki and El-Haddad, 2017; Vucković et al., 2009). Given the rapid pace at which new NSO are entering the recreational drug market, it seems prudent to carry out more preclinical research with the drugs to determine their adverse effects such as abuse liability, tolerance development, and lethality. The findings from such studies will inform clinicians, forensic scientists, law enforcement personnel and policymakers who are involved with responding to the current opioid overdose crisis.

\section{Acknowledgements}

This research was generously supported by the Intramural Research Program of the National Institute on Drug Abuse (NIDA) (DA00523), by research grants from NIDA (DA06241 and DA07242), and grants from the Mayday Fund and the Peter F. McManus 


\section{Charitable Trust to GWP. This research was funded in part through the NIH/NCI Cancer Center Support Grant P30 CA008748 and the NIMH Psychoactive Drug Screening Program.}

\section{References}

Alburges, M.E., Hanson, G.R., Gibb, J.W., Sakashita, C.O., Rollins, D.E., 1992. Fentany receptor assay. II. utilization of a radioreceptor assay for the analysis of fentanyl analogs in urine. J. Anal. Toxicol. 16, 36-41.

Amlani, A., McKee, G., Khamis, N., Raghukumar, G., Tsang, E., Buxton, J.A., 2015. Why the FUSS (Fentanyl Urine Screen Study)? A cross-sectional survey to characterize an emerging threat to people who use drugs in British Columbia, Canada. Harm Reduct. J. 12, 54-64.

Armenian, P., Olson, A., Anaya, A., Kurtz, A., Ruegner, R., Gerona, R.R., 2017. Fentanyl and a novel synthetic opioid U-47700 masquerading as street "Norco" in central California: a case report. Ann. Emerg. Med. 69, 87-90.

Bolan, E.A., Pan, Y.X., Pasternak, G.W., 2004. Functional analysis of MOR-1 splice variants of the mouse mu opioid receptor gene Oprm. Synapse 51, 11-18.

Brandt, S.D., King, L.A., Evans-Brown, M., 2014. The new drug phenomenon. Drug Test. Anal. 6, 587-597.

Cheney, B.V., Szmuszkovicz, J., Lahti, R.A., Zichi, D.A., 1985. Factors affecting binding of trans-N-[2-(methylamino)cyclohexyl]benzamides at the primary morphine receptor. J. Med. Chem. 28, 1853-1864.

Drug Enforcement Administration, 2016a. Emerging Threat Report Mid-year 2016 [DEA Emerging Trends Report]. Available at: https://ndews.umd.edu/sites ndews.umd.edu/files/pubs/emergingthreatreport2016mid-year.pdf. (Accessed 25 May 2017).

Drug Enforcement Administration, 2016b. Schedules of Controlled Substances: Temporary Placement of Butyryl Fentanyl and Beta-hydroxythiofentanyl into Schedule I [Docket No. DEA-434F]. Available at: https://www.deadiversion. usdoj.gov/fed_regs/rules/2016/fr0512_2.htm. (Accessed 25 May 2017).

Drug Enforcement Administration, 2016c. Schedules of Controlled Substances: Temporary Placement of U-47700 into Schedule I [Docket No. DEA-440]. Available at: https://www.deadiversion.usdoj.gov/fed_regs/rules/2016/fr1114. htm. (Accessed 25 May 2017).

Drug Enforcement Administration, 2016d. Counterfeit Prescription Pills Containing Fentanyls, a Global Threat [DEA Intelligence Brief]. Available at: https://www. dea.gov/docs/Counterfeit\%20Prescription\%20Pills.pdf. (Accessed 25 May 2017).

Elliott, S.P., Brandt, S.D., Smith, C., 2016. The first reported fatality associated with the synthetic opioid 3,4-dichloro-N-[2-(dimethylamino)cyclohexyl]-N-methylbenzamide (U-47700) and implications for forensic analysis. Drug Test. Anal. 8 $875-879$.

European Monitoring Centre for Drugs and Drug Addiction, 2014. EMCDDA-europol Joint Report on a New Psychoactive Substance: 1-cyclohexyl-4-(1,2 diphenylethyl)piperazine ('MT-45') [Risk Assessment Report]. Available at: http://www.emcdda.europa.eu/publications/joint-reports/MT-45. (Accessed 25 May 2017).

Frank, R.G. Pollack, H.A., 2017. Addressing the fentanyl threat to public health N. Engl. J. Med. 376, 605-607.

Fujimura, H., Tsurumi, K., Nozaki, M., Hori, M., Imai, E., 1978. Analgesic activity and opiate receptor binding of 1-cyclohexyl-4-(1,2-diphenylethyl)piperazine. Jpn. J. Pharmacol. 28, 505-506.

Gladden, R.M., Martinez, P., Seth, P., 2016. Fentanyl law enforcement submissions and increases in synthetic opioid-involved overdose deaths - 27 states, 20132014. MMWR Morb. Mortal. Wkly. Rep. 65, 837-843.

Green, T.C., Gilbert, M., 2016. Counterfeit medications and fentanyl. JAMA Intern. Med. 176, 1555-1557.

Grinnell, S.G., Ansonoff, M., Marrone, G.F., Lu, Z., Narayan, A., Xu, J., Rossi, G., Majumdar, S., Pan, Y.X., Bassoni, D.L., Pintar, J., Pasternak, G.W., 2016. Mediation of buprenorphine analgesia by a combination of traditional and truncated mu opioid receptor splice variants. Synapse 70, 395-407.

Hayes, A.G., Sheehan, M.J., Tyers, M.B., 1985. Determination of the receptor selectivity of opioid agonists in the Guinea-pig ileum and mouse vas deferens by use of beta-funaltrexamine. Br. J. Pharmacol. 86, 899-904.

Helander; A., Bäckberg, M., Beck, O., 2014. MT-45, a new psychoactive substance associated with hearing loss and unconsciousness. Clin. Toxicol. (Phila.) 52, 901-904.

Helander, A. Bradley, M. Hasselblad, A, Norlén, L, Vassilaki, I. Bäckbero M. Lapins, J., 2017. Acute skin and hair symptoms followed by severe, delayed eye complications in subjects using the synthetic opioid MT-45. Br. J. Dermatol 176 1021-1027.

Higashikawa, Y., Suzuki, S, 2008 Studies on 1-(2-phenethyl)-4-(N-propionylanilino)piperidine (fentanyl) and its related compounds. VI. Structure-analgesic activity relationship for fentanyl, methyl-substituted fentanyls and other analogues. Forensic Toxicol. 26, 1-5.

Kroeze, W.K., Sassano, M.F., Huang, X.P., Lansu, K., McCorvy, J.D., Giguère, P.M., Sciaky, N., Roth, B.L., 2015. PRESTO-Tango as an open-source resource for interrogation of the druggable human GPCRome. Nat. Struct. Mol. Biol. 22, $362-369$.
Loew, G., Lawson, J., Toll, L., Frenking, G., Berzetei-Gurske, I., Polgar, W., 1988. Structure activity studies of two classes of beta-amino-amides: the search for kappa-selective opioids. NIDA Res. Monogr. 90, 144-151.

Lu, Z., Xu, J., Rossi, G.C., Majumdar, S., Pasternak, G.W., Pan, Y.X., 2015. Mediation of opioid analgesia by a truncated 6-transmembrane GPCR. J. Clin. Invest. 125, 2626-2630.

Madras, B.K., 2017. The growing problem of new psychoactive substances (NPS). Curr. Top. Behav. Neurosci. 32, 1-18.

Majumdar, S., Burgman, M., Haselton, N., Grinnell, S., Ocampo, J., Pasternak, A.R., Pasternak, G.W., 2011a. Generation of novel radiolabeled opiates through siteselective iodination. Bioorg. Med. Chem. Lett. 21, 4001-4004.

Majumdar, S., Grinnell, S., Le Rouzic, V., Burgman, M., Polikar, L., Ansonoff, M., Pintar, J., Pan, Y.X., Pasternak, G.W., 2011b. Truncated G protein-coupled mu opioid receptor MOR-1 splice variants are targets for highly potent opioid analgesics lacking side effects. Proc. Natl. Acad. Sci. U. S. A. 108, 19778-19783.

Marrone, G.F., Le Rouzic, V., Varadi, A., Xu, J., Rajadhyaksha, A.M., Majumdar, S., Pan, Y.X., Pasternak, G.W., 2017. Genetic dissociation of morphine analgesia from hyperalgesia in mice. Psychopharmacol. Berl. 234, 1891-1900.

McIntyre, I.M., Trochta, A., Gary, R.D., Wright, J., Mena, O., 2016. An acute butyrfentanyl fatality: a case report with postmortem concentrations. J. Anal. Toxicol. 40, 162-166.

Mohr, A.L., Friscia, M., Papsun, D., Kacinko, S.L., Buzby, D., Logan, B.K., 2016. Analysis of novel synthetic opioids U-47700, U-50488 and furanyl fentanyl by LC-MS/MS in postmortem casework. J. Anal. Toxicol. 40, 709-717.

Natsuka, K., Nakamura, H., Uno, H., Umemoto, S., 1975. Studies on 1-substituted 4(1,2-diphenylethyl)piperazine derivatives and their analgesic activities. J. Med. Chem. 18, 1240-1244.

Nishimura, H., Uno, H., Shimokawa, N., Shimizu, M., Nakamura, H., inventors, 1976. Dainippon Pharmaceutical Co. Ltd., Assignee. 1-substituted-4-(1,2diphenylethyl)-piperazine Derivatives and Their Salts and the Preparation Thereof. US patent 3,957,788.

United Nations Office of Drug and Crime, 2016. World Drug Report. Available at: http://www.unodc.org/doc/wdr2016/WDR_2016_Chapter_1_ATS_NPS.pdf. (Accessed 25 May 2017).

Nozaki, M., Niwa, M., Imai, E., Hori, M., Fujimura, H., 1983. (1,2-Diphenylethyl) piperazines as potent opiate-like analgesics; the unusual relationships between stereoselectivity and affinity to opioid receptor. Life Sci. 33 (Suppl 1), 431-434.

Pan, Y.X., Xu, J., Xu, M., Rossi, G.C., Matulonis, J.E., Pasternak, G.W., 2009. Involvement of exon 11-associated variants of the mu opioid receptor MOR-1 in heroin, but not morphine, actions. Proc. Natl. Acad. Sci. U. S. A. 106, 4917-4922.

Pasternak, G.W., 2014. Opioids and their receptors: are we there yet? Neuropharmacology 76, 198-203.

Poklis, J., Poklis, A., Wolf, C., Hathaway, C., Arbefeville, E., Chrostowski, L., Devers, K., Hair, L., Mainland, M., Merves, M., Pearson, J., 2016. Two fatal intoxications involving butyryl fentanyl. J. Anal. Toxicol. 40, 703-708.

Prekupec, M.P., Mansky, P.A., Baumann, M.H., 2017. Misuse of novel synthetic opioids: a deadly new trend. J. Addict. Med. 11, 256-265.

Rudd, R.A., Seth, P., David, F., Scholl, L., 2016. Increases in drug and opioid-involved overdose deaths - United States, 2010-2015. MMWR Morb. Mortal. Wkly. Rep. $65,1445-1452$.

Selley, D.E., Sim, LJ., Xiao, R., Liu, O. Childers, S.R., 1997. Mu-Opioid receptorstimulated guanosine-5'-O-(gamma-thio)-triphosphate binding in rat thalamus and cultured cell lines: signal transduction mechanisms underlying agonist efficacy. Mol. Pharmacol. 51, 87-96.

Siddiqi, S., Verney, C., Dargan, P., Wood, D.M., 2015. Understanding the availability, prevalence of use, desired effects, acute toxicity and dependence potential of the novel opioid MT-45. Clin. Toxicol. (Phila.) 53, 54-59.

Suzuki, J., El-Haddad, S., 2017. A review: fentanyl and non-pharmaceutical fentanyls. Drug Alcohol. Depend. 171, 107-116.

Szmuszkowicz, J., inventor, 1978. The Upjohn Company, Assignee. Analgesic N-(2aminocycloaliphatic)benzamides. US patent 4,098,904.

US-China Economic and Security Review Commission, 2017. Fentanyl: China's Deadly Export to the United States. Available at: https://www.uscc.gov/sites/ default/files/Research/USCC\%20Staff\%20Report_Fentanyl-China\%E2\%80\%99s\% 20Deadly\%20Export\%20to\%20the\%20United\%20States020117.pdf. (Accessed 25 May 2017).

Váradi, A., Hosztafi, S., Le Rouzic, V., Tóth, G., Urai, Á., Noszál, B., Pasternak, G.W., Grinnell, S.G., Majumdar, S., 2013. Novel 6â-acylaminomorphinans with analgesic activity. Eur. J. Med. Chem. 69, 786-789.

Váradi, A., Marrone, G.F., Eans, S.O., Ganno, M.L., Subrath, J.J., Le Rouzic, V., Hunkele, A., Pasternak, G.W., McLaughlin, J.P., Majumdar, S., 2015. Synthesis and characterization of a dual kappa-delta opioid receptor agonist analgesic blocking cocaine reward behavior. ACS Chem. Neurosci. 6, 1813-1824.

Vucković, S., Prostran, M., Ivanović, M., Dosen-Mićović, L., Todorović, Z., Nesić, Z., Stojanović, R., Divac, N., Miković, Z., 2009. Fentanyl analogs: structure-activityrelationship study. Curr. Med. Chem. 16, 2468-2474.

Woods, J., Medzihradsky, F., Smith, C., Winger, G., Gmerek, D., 1988. Evaluation of new compounds for opioid activity: 1987 annual report. NIDA Res. Monogr. 81, 579-581. 